\title{
OPEM
}

www.opem.org

Oriental Pharmacy and Experimental Medicine 2009 9(4), 339-349

DOI 10.3742/OPEM.2009.9.4.339

\section{Dose dependent effect of benzene extract of Ocimum sanctum leaves on cauda epididymal spermatozoa of albino rats}

\author{
Mukhtar Ahmed ${ }^{1,2}$, R Nazeer Ahamed ${ }^{1}$, RH Aladakatti ${ }^{1,3, *}$ and Ghodesawar MG ${ }^{1,4}$ \\ ${ }^{1}$ Department of Post-Graduate Studies and Research in Zoology, Karnatak University, Dharwad-580003, India; \\ ${ }^{2}$ College of Science, King Saud University, Post Box 2455, Riyadh 11451, Kingdom of Saudi Arabia; ${ }^{3}$ Central \\ Animal Facility, Indian Institute of Science, Bangalore-560012, India; ${ }^{4}$ Anjuman Arts, Sciences \& Commerce \\ College, Bijapur-586101, India
}

Received for publication July 25, 2008; accepted March 20, 2009

\begin{abstract}
SUMMARY
An attempt has been made to assess whether the dose dependent effect of benzene extract of Ocimum sanctum leaves on the morphological changes in the cauda epididymal spermatozoa and sperm parameters in male albino rats. Scanning Electron Microscope observations illustrate the disturbance in plasma membrane as well as acrosomal membrane. Most of the sperms appear morphologically abnormal in the mid region of the tail; there is formation of balloon like cytoplasmic droplet. Sperm parametric study exhibits decrease in the total sperm count, sperm motility, forward velocity and increase in the percentage of abnormal sperms in dose dependent manner on treatment benzene extract of Ocimum sanctum leaves. The results suggest that the effects may have resulted from a general disturbance in the proteins and alteration in cauda epididymal milieu probably due to androgen deficiency consequent upon antiandrogenic property of Ocimum sanctum leaves.
\end{abstract}

Key words: Ocimum sanctum; Cauda epididymis; Spermatozoa; Scanning Electron Microscope; Albino rats

\section{INTRODUCTION}

The plant products affecting aspects of male reproduction, brings about the effect through either of two mechanisms namely, estrogenic or antiandrogenic effect (Kasinathan et al., 1972). The leaves, flowers, fruits and seeds of several plants are known to possess estrogen and antiandrogen like substances, which act on the reproductive system of male and female rats and thus inhibiting fertility (Chinoy and Geetha Ranga, 1983; Malini et

*Correspondence: RH Aladakatti, Central Animal Facility, Indian Institute of Science, Bangalore-560012, India. E-mail: ravindranath@caf.iisc.ernet.in al., 1985; Akbarsha et al., 1990; Aladakatti and Nazeer Ahamed, 1999). From the literature of medicinal plants, it has been established that different parts of the plant source causes reduction in sperm count, sperm motility and increase in relative percentage of the abnormal sperm in mouse and rats (Chinoy et al., 1995; Akbarsha and Averal, 1996; Aladakatti et al., 2001; Girini et al., 2005) and results shown that androgen is essential for the maturation, motility and survival of sperms in the epididymis. Ocimum (O.) sanctum Linn. (Laiatae family) is an important medicinal plant, commonly called tulsi, has been recognized for its unique properties. It is used as antibacterial, 
insecticidal, diaphoretic in malarial fever, antiperiodic in gastric and genitourinary systems (Nadkarni, 1954; Kirtikar and Basu, 1975). Additionally, the leaves of O. sanctum; a) significantly altered the weight of testis, reducing the sperm count and motility (Seth et al., 1981); b) cause a decrease in $\mathrm{pH}$, hypertonic environment and differences in concentration of chemical substances of biological importance i.e., mucoprotein, alkaline phosphatase and acid phosphates (Kashinathan et al., 1972); c) reduce the mating behaviour of both male and female albino rats (Khanna et al., 1986; Kantak and Gogate, 1992; Sardessai et al., 1999); and d) significantly altered the sperm count, motility, velocity and fructose contained in the cauda epididymis of male albino rats (Mukhtar Ahmed et al., 2002). The review of literature indicates that the ultra structural studies on the effect of dose dependent of benzene extract of $O$. sanctum leaves on the morphological changes in the sperms of albino rats is lack. Hence, the present study was aimed to elucidate the effect of different concentrations of benzene extract of $O$. sanctum leaves on sperm parameters and morphological changes in the rat cauda epididymal sperms by scanning electron microscope.

\section{MATERIALS AND METHODS}

\section{Preparation of test material}

Fresh $O$. sanctum leaves were collected and dried in shade. A voucher specimen (Zoo/herb/File No.47Acc.No.22) was deposited at Zoology Department, Karnatak University, Dharwad, India. The dried leaves were coarsely powdered and subjected to soxheltation process to get the benzene extract. Extract thus obtained was allowed to dry and stored in a dessicator at $4^{\circ} \mathrm{C}$.

\section{Animals and treatment}

Colony bred healthy adult male albino rats (Wistar strain) weighing 180 - $200 \mathrm{~g}$ were utilized for experiments. All animals were proven fertility and obtained from the rat colony maintained in the department. They were housed at a temperature of $26 \pm 2^{\circ} \mathrm{C}$ and exposed to $13-14 \mathrm{~h}$ of daylight and maintained on a standard diet and water was given ad libitum. The benzene extract is then mixed with propylene glycol as required and administered orally (gavage) to the experimental animals (WHO, 1983).

\section{Study protocol}

The rats were divided into 4 groups; each consisting of 5 animals is as Group I: Control animals received equal volume of equivalent concentration of propylene Glycol orally for 15 days. Group II: The animals were given a daily dose of $150 \mathrm{mg} / \mathrm{kg}$ body weight of benzene extract in $1.5 \mathrm{ml}$ of propylene Glycol for a period of 15 days. Group III: The animals were given a daily dose of $200 \mathrm{mg} / \mathrm{kg}$ body weight of benzene extract in $2 \mathrm{ml}$ of propylene Glycol for a period of 15 days. Group IV: The animals were given a daily dose of $250 \mathrm{mg} / \mathrm{kg}$ body weight of benzene extract in 2.5 $\mathrm{ml}$ of propylene Glycol for a period of 15 days. The animals were sacrificed by cervical dislocation $24 \mathrm{~h}$ after the last dose.

\section{Sperm analysis}

The cauda epididymis was chopped into phosphate buffered glucose saline (PBGS) [composition: $\mathrm{NaCl}$ $50 \mathrm{mM} ; \mathrm{Na}_{2} \mathrm{HPO}_{4} 200 \mathrm{mM}$; glucose $200 \mathrm{mM}$ and $\mathrm{KH}_{2} \mathrm{PO}_{4} 26 \mathrm{mM}$ ]. The debris was removed and a clear suspension, viz; the epididymal plasma was used for the analysis of total sperm count, sperm motility, forward velocity and relative percentage of abnormal sperms in male albino rats.

The total sperm count and motility were calculated according to the method of Besley et al. (1980) using Neubauer's haemocytometer. Briefly, to increase the accuracy of sperm count, the epididymal plasma was diluted with a spermicidal solution, prepared by dissolving $5 \mathrm{~g}$ of sodium bicarbonate $\left(\mathrm{NaHCO}_{3}\right)$ and $1 \mathrm{ml}$ of $40 \%$ formaldehyde in $100 \mathrm{ml}$ of normal saline. A twenty times dilution 
was made using W.B.C pipette, which was thoroughly mixed and one drop was added to both sides of Neubauer haemocytometer. The spermatozoa were allowed to settle down in the haemocytometer by keeping them in a humid chamber for one hour. The sperm count was done in R.B.C counting 5 major squares. The total number of sperms were counted in all the major squares and calculated as follows:

Total number of sperms $/ \mathrm{ml}$ plasma $=$ Total number of sperms per square/Total volume per square $\left(10^{-4}\right) \times$ dilution factor $(20)$

Similarly the total number of motile sperms was calculated, using phosphate buffer saline instead of spermicidal solution. The forward velocity of the sperm was calculated according to the method of Ratnasoorya (1984). Briefly, the epididymal plasma was suspended in phosphate buffer saline, cleared the tissue debris and a clear solution was used for the assessment of average forward velocity of sperms. The assessment was made under light microscope, fitted with a movable mechanical stage and a calibrated ocular micrometer, at $400 \times$ magnification. A drop of sperm suspension was transferred to a clean glass slide and the initial place and time of each sperm was recorded. The time taken for forward movement of sperm from the initial place within microscopic field was recorded using a stop watch. The procedure was repeated for 10 spermatozoa in each sample and the average forward velocity of sperm was calculated and expressed as $\mathrm{mm} / \mathrm{s}$. The relative proportion of abnormal sperms was analyzed according to the method of Bauer et al. (1974). Briefly, equal volume of cauda epididymal plasma and $5 \% \mathrm{NaHCO}_{3}$ were taken in a centrifuge tube, mixed well and centrifuged for $5 \mathrm{~min}$ at 4,000 $\times g$. The supernatant was discarded and to the precipitate $5 \mathrm{ml}$ of normal saline was added, mixed well and centrifuged again. The procedure was repeated 2 to 3 times and a clear precipitate was obtained. To the final precipitate few drops of normal saline were added, mixed thoroughly and a smear was prepared on a clean slide. The smear was dried at room temperature, fixed by heating it over the flame for two to three seconds. Then the smear was flushed with $95 \%$ alcohol, drained and dried. It was stained in Ziehl Neelson's Carbol Fuchsin diluted with equal volume of $95 \%$ alcohol for $3 \mathrm{~min}$ and counter stained with 1:3 (v/v) aqueous solution of Loeffer's methylene blue for 2 min. After staining, the smear was rinsed in water and dried in air. The abnormal sperms included categories like double tailed, detached head, detached tail, mid piece bending and irregular head. The relative proportion of the normal and abnormal sperms was from the smear and expressed in terms of percentage.

\section{Scanning electron microscopic (SEM) study}

Twenty-four hours after the last dose, the control and treated animals were sacrificed by cervical dislocation. Preparation of rat spermatozoa for SEM studies was per performed as described elsewhere (Aladakatti and Nazeer Ahamed 1999). Briefly, a drop of cauda epididymal plasma was fixed in $2 \%$ glutaraldehyde, centrifuged and washed with $0.1 \mathrm{M}$ Sodium cacodylate buffer (pH.7.2), centrifuged again in distilled water till the buffer solution was washed out and a thin film was applied on a cover slip, dried, sputter coated with gold and finally observed under scanning electron microscope (Model. LEO 435 VP Detector SL.1. LEO Electron Microscopy ltd Cambridge, England) at Central Food and Technological Research Institute, Mysore (India).

\section{Statistical analysis}

The data were presented as mean \pm S.E.M. The comparison of data for statistically significant differences was done using students ' $t$ ' test and a probability level of $P \leq 0.01$ and $P \leq 0.001$ were considered as significant and highly significant, respectively. 


\section{RESULTS}

\section{Sperm analysis}

Analysis of sperm parameters, such as total sperm count, total number of motile sperm, forward velocity of the sperm and percentage of abnormal sperm of the cauda of epididymal plasma were carried out in the control and all the treated animals. The control rats showed $56.40 \times 10^{4}$ total numbers of sperm $/ \mathrm{ml}$ epididymal fluid, $52.40 \times$ $10^{4}$ numbers of motile sperm $/ \mathrm{ml}$ epididymal fluid with a speed of $127.63 \mathrm{~mm} / \mathrm{s}$ and $11.40 \%$ of abnormal sperm were recorded (Table 1).

Where as in the benzene extract of O.sanctum leaves treated animals (Group II, III and IV), the abnormal sperm in cauda epididymal plasma of albino rats are doses dependent. With a dose of 150 $\mathrm{mg} / \mathrm{kg}$ body weight of benzene extract treated animals (Group II), showed a significant $(P \leq 0.01)$ decrease in total sperm count $(75 \%)$, total number of motile sperm $(75 \%)$ and forward velocity of the sperm $(86 \%)$. There was a highly significant $(P \leq 0.001)$ increase in the percentage of abnormal sperm $(37.3 \%)$.

While, in dose of 200 and $250 \mathrm{mg} / \mathrm{kg}$ body weight of benzene extract treated animals (Group III and GroupIV, respectively), showed a highly significant decrease $(P \leq 0.001)$ in total sperm count (65\% and $56 \%$, respectively), total number of motile sperm ( $58 \%$ and $45 \%$, respectively), forward velocity of sperm ( $62 \%$ and $49 \%$, respectively) and a highly significant increase $(P \leq 0.001)$ in the percentage of abnormal sperm $(47.0 \%$ and $54.4 \%$, respectively) when compared to control animals.

\section{SEM observations of rat sperms from cauda epididymal plasma}

Electron Microscopic observations of the cauda epididymal sperm of control rats (Group I) showed normal parts (Fig. 1). Perforatorium and acrosome are covered with the plasma membrane. A distinguish acrosome is covered with acrosomal membrane. The whole spermatozoon is intact with all the membranes and organelles.

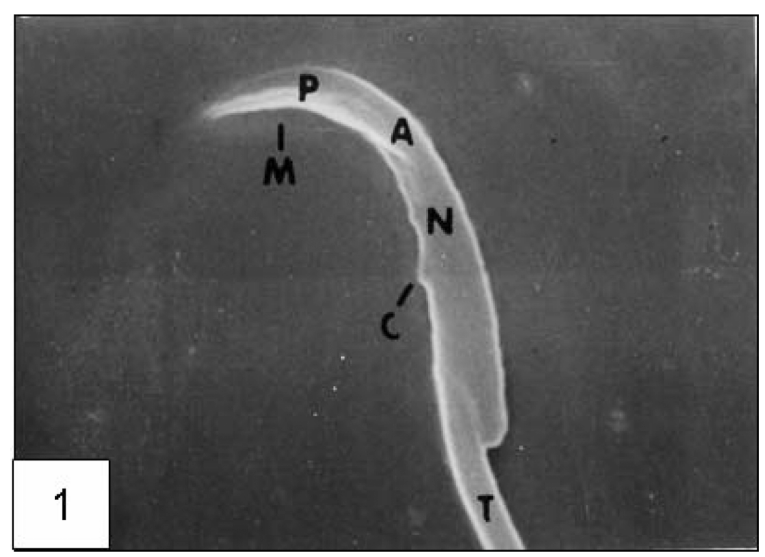

Fig. 1. Electron micrograph (EM) of cauda epididymal spermatozoa of control rat exhibits normal parts. A acrosome; C - post nuclear cap; M - plasma membrane; $\mathrm{N}$ - nucleus; $\mathrm{P}$ - perforatium and $\mathrm{T}$ - tail region. $4.56 \mathrm{kx}$.

Table 1. Effect of O.sanctum leaves (benzene extract) on various sperm parameters of cauda epididymal plasma in albino rats (values are expressed as mean \pm S.E.M. of 5 animals)

\begin{tabular}{|c|c|c|c|c|c|}
\hline Group & Treatment & $\begin{array}{c}\text { Sperm count } \\
\left(\text { Total No. } \times 10^{4} / \mathrm{ml}\right)\end{array}$ & $\begin{array}{c}\text { Motile sperm } \\
\left(\text { Total No. } \times 10^{4} / \mathrm{ml}\right)\end{array}$ & $\begin{array}{c}\text { Forward velocity } \\
(\mu \mathrm{m} / \mathrm{s})\end{array}$ & $\begin{array}{c}\text { Abnormal sperms } \\
(\%)\end{array}$ \\
\hline I & control & $\begin{array}{c}56.40 \pm 1.39 \\
(100 \%)\end{array}$ & $\begin{array}{c}52.40 \pm 2.15 \\
(100 \%)\end{array}$ & $\begin{array}{c}127.63 \pm 2.75 \\
(100 \%)\end{array}$ & $\begin{array}{c}11.40 \pm 0.26 \\
(100 \%)\end{array}$ \\
\hline II & $\begin{array}{c}150 \mathrm{mg} / \mathrm{kg} \text { body weight of } \\
\text { benzene extract }\end{array}$ & $\begin{array}{l}42.35 \pm 0.30^{*} \\
(75 \%)\end{array}$ & $\begin{array}{l}39.20 \pm 0.45^{*} \\
\quad(75 \%)\end{array}$ & $\begin{array}{c}110.40 \pm 0.33^{*} \\
(86 \%)\end{array}$ & $\begin{array}{l}42.62 \pm 0.58^{* *} \\
(37.3 \%)\end{array}$ \\
\hline III & $\begin{array}{c}200 \mathrm{mg} / \mathrm{kg} \text { body weight of } \\
\text { benzene extract }\end{array}$ & $\begin{array}{l}37.15 \pm 0.86^{* *} \\
(65 \%)\end{array}$ & $\begin{array}{l}30.50 \pm 0.30^{* *} \\
(58 \%)\end{array}$ & $\begin{array}{c}80.15 \pm 0.63^{* *} \\
(62 \%)\end{array}$ & $\begin{array}{c}53.65 \pm 0.64^{* *} \\
(47.0 \%)\end{array}$ \\
\hline IV & $\begin{array}{c}250 \mathrm{mg} / \mathrm{kg} \text { body weight of } \\
\text { benzene extract }\end{array}$ & $\begin{array}{c}32.00 \pm 1.22^{* *} \\
(56 \%)\end{array}$ & $\begin{array}{l}24.00 \pm 1.70^{* *} \\
(45 \%)\end{array}$ & $\begin{array}{c}63.16 \pm 1.71^{* *} \\
(49 \%)\end{array}$ & $\begin{array}{l}62.03 \pm 1.95^{* *} \\
(54.4 \%)\end{array}$ \\
\hline
\end{tabular}

${ }^{*} P \leq 0.01, * * P \leq 0.001$. 


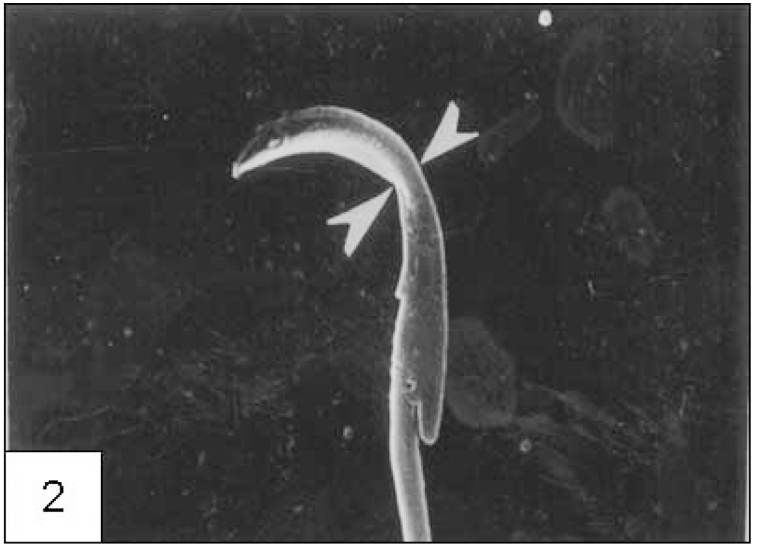

Fig. 2. EM of spermatozoa of rats treated with 150 $\mathrm{mg} / \mathrm{kg}$ body weight of benzene extract. There is slight disturbance in the plasma membrane as well as in the acrosomal membrane and there is slight dorsoventral constriction (arrows) in the head region of spermatozoon. $4.39 \mathrm{kx}$.

Whereas in the benzene extract of $O$. sanctum leaves treated animals (Group II, III and IV), the severity of morphological changes are doses dependent. With a dose of $150 \mathrm{mg} / \mathrm{kg}$ body weight of benzene extract treated animals (Group II), there is slight disturbance in plasma membrane as well as acrosomal membrane in the head region of rat sperm, without any distinct formation of cytoplasmic droplet in the mid region of tail (Fig. 2).
With a dose of $200 \mathrm{mg} / \mathrm{kg}$ body weight of benzene extract treated animals (Group III), most of the sperms exhibit abnormal features morphologically such head with membrane disruption (Fig. 3) and agglutination and cytoplasmic bulging/droplet are seen distinctly in the mid portion of sperms tail (Fig. 4). Further, the maximum dose of $250 \mathrm{mg} / \mathrm{kg}$ body weight of benzene extract treated animals (Group IV), results in head of spermatozoa with distinct indication of severe effect at the anterior region. The plasma membrane along the entire length of sperm head is disrupted, the middle region of the sperm head is constricted dorsoventrally and there is serration at the connective piece of the spermatozoa (Fig. 5). Increase in the agglutination of sperm with cytoplasmic bulging/droplet are seen distinct visibility of balloon like in the mid portion of the most spermatozoa (Fig. 6).

\section{DISCUSSION}

Various plants like chloroform extracts of the bark of Quassia amara (Parveen et al., 2003); hydroalcoholic extract from Lantana camara leaves (de Mello et al., 2003); aqueous crude extract of the bark of Carica papaya (Kusemiju et al., 2002); aqueous extracts of Ruta graveolens (Khouri and El-Akawi, 2005);



Figs. 3 and 4. EM of spermatozoa of rats treated with $200 \mathrm{mg} / \mathrm{kg}$ body weight of benzene extract. Fig. 3. There is disturbance in the plasma as well as acrosome membranes in head region of spermatozoa. Also there is dorsoventral constriction in the head (arrows) $2.63 \mathrm{kx}$. Fig 4. There is swelling at tail region (cytoplasmic droplet) in the mid portion of the tail region (arrows, ST). $2.00 \mathrm{kx}$. 

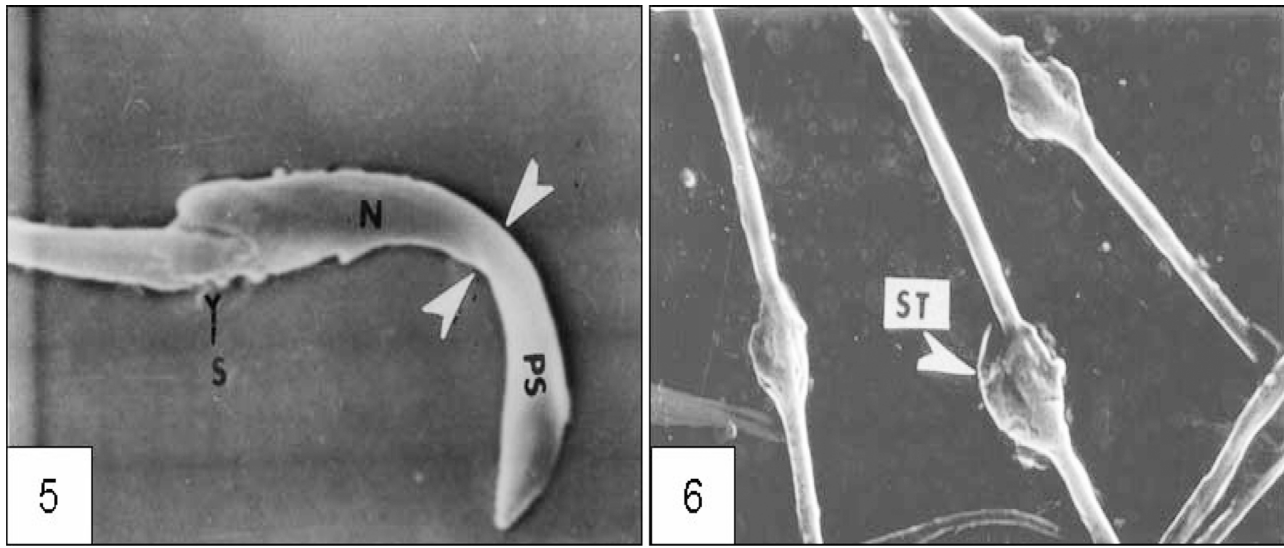

Figs. 5 and 6. EM of spermatozoa of rats treated with $250 \mathrm{mg} / \mathrm{kg}$ body weight of benzene extract. Fig. 5. The perforatium (Sub-acrosomal material), swells (PS) and the middle region of the sperm head is constricted dorsoventrally (arrows). There is serration $(S)$ at the connective piece of the spermatozoa. A5.56kx. Fig. 6. There is increase of swelling at tail region in the mid portion of the tail region rat spermatozoa (arrows, ST). $5.93 \mathrm{kx}$.

methanol sub-fraction of the seeds of Carica papaya (Lohiya et al., 2006); methanol extract of Dendrophthoe falcate (Gupta and Kachhawa, 2007); aqueous extract of Peganum harmala (El-Dwairi and Banihani, 2007); marjoram volatile oil and grape seed extract on ethanol administration (El-Ashmawy et al., 2007) have been reported to possess antifertility activity by exhibiting reduced the sperm count, motility, fertility, viability and increased abnormal sperms in mice and rats. It was suggested that the extract causes androgen depletion at the target level, particularly in the cauda epididymis thereby affecting physiological maturation of the sperm (Chinoy et al., 1995).

Studies involving hypophysectomy, castration and androgen replacement therapy reveal that androgen is essential for physiological maturation and survival of the spermatozoa in the epididymis (Dyson and Orgebein-Crist, 1973; Setty et al., 1977). It is known that sperm reproduction doesn't proceed optimally to completion without a continuous androgen supply (Brooks, 1981). Androgen may affect the sperm directly or through modification of epididymal milieu. Several facts suggest a direct effect on the organ (Blaquier, 1971). It has been shown that androgens are essential for survival and motility of spermatozoa in the rat epididymis, cauda region appears to be the most favourable site. Sperm possess two principal attributes, viz, motility and the fertilizing ability, which are prerequisites for fertilization. Any negative impact on motility would seriously affect the fertilizing ability (Murugavel et al., 1989).

In the present study, on treatment with benzene extract of $O$. sanctum leaves exhibits reducing sperm count, motility and sperm speed in dose dependent manner. It was suggested that the extract causes androgen depletion at the target level, particularly in the cauda epididymis thereby affecting physiological maturation of the sperm (Chinoy et al., 1995). In this study, the observations made and are supported from studies of Chloroform extract of the bark of Quassia amara (Parveen et al., 2003); aqueous crude extract of the bark of Carica papaya (Kusemiju et al., 2002); purified compounds and methanol sub-fraction of the seeds of Carica papaya (Lohiya et al., 2005, 2006); methanol extract of Dendrophthoe falcate (Gupta and Kachhawa, 2007); aqueous extract of Peganum harmala (ElDwairi and Banihani, 2007) and marjoram volatile oil and grape seed extract on ethanol administration (El-Ashmawy et al., 2007). 
The occurrence of morphologically abnormal spermatozoa is a diagnostic aid for infertility besides using other characteristics such as motility, density and viability. Semen sample per ejaculate containing more than $20 \%$ of abnormal sperm is considered poorly fertile (Bauer et al., 1974). A high incidence of abnormality is associated with infertility (Macleod, 1970). The relative distribution of the different morphological types of spermatozoa present in a sample provides the most significant clue to discriminate between fertile and infertile samples (Gopalkrishnan et al., 1992). Sperm movement is reportedly different between morphologically normal and abnormal spermatozoa (Katz et al., 1982). The assessment of morphology is good indicator of fertilizing ability of spermatozoa and the increased incidence of headless spermatozoa in the infertile group confirms that this is associated with infertility (Rogers et al., 1983; Gopalkrishnan et al., 1989).

In the present study, on treatment with benzene extract of $O$. sanctum leaves exhibits significant increase in sperm anomalies viz., Head abnormalities were amorphous, hookless, banana-shaped, formation of folded, coiled and bent. Incidences of abnormal sperms were found elevated by dose dependent. Besides these morphological alterations, many sperm tails appeared in the smears of treated rats with detached heads. The present study is supported from studies of treated with chloroform extracts of the bark of Quassia amara (Parveen et al., 2003); hydroalcoholic extract from Lantana camara leaves (de Mello et al., 2003); aqueous crude extract of the bark of Carica papaya (Kusemiju et al., 2002); aqueous extract from leaves of Achillea millefolium (Dalsenter et al., 2004); purified compounds of the seeds of Carica papaya (Lohiya et al., 2005).

Androgens are essential for survival and motility of spermatozoa in the rat epididymis. Sperm motility is an important attribute of sperm quality as there is a good correlation between sperm motility on one hand and plasma membrane integrity and conception rates on the other. The combination of medroxy progesterone acetate and testosterone enanthate is a contraceptive, which causes loss of sperm motility and structural defects exerted by changing the membrane permeability in monkey epididymis (Rajalakshmi et al., 1990). There is an evidence of acrosomal loss or damage as well as other abnormalities observed in caudal region of rat sperm due to this treatment suggesting that these sperms were probably unable to fertilize the ovum (Rao and Roy, 1993).

The acrosome contains several enzymes which are secreted by the Golgi apparatus and endoplasmic reticulum. The production of enzymes destined for the acrosome is regulated to some degree by testosterone (Morton, 1975). From histochemical evidence the presence of carbohydrates or polysaccharides in the head of the spermatozoa, which are associated with various enzymatic activities is indicated. Earlier studies have been reported that morphological changes in the head of spermatozoa in general and the acrosome in particular may have resulted from an alteration in the epididymal milieu of rats treated with crude leaf extract of A.indica (Aladakatti and Nazeer Ahamed, 1999) and alcohol seed extract of Momordica charantia (Girini et al., 2005) suggested that these changes are due to a general disturbance of carbohydrates or polysaccharides present in the acrosome of the sperm head (Aladakatti and Nazeer Ahamed, 1999). In this study, most of the sperm abnormalities are dose dependent. The mid region of sperm heads show dorsoventrally constricted with the bulged sub acrosomal material. The disrupted plasma membrane and acrosomal membrane particularly at the anterior region, on treatment with benzene extract of $O$. sanctum leaves, are probably due to the general disturbance in the proteins.

Studies have been reported that extracts from different plants namely gossypol, Solanum xanthocarpum, Carica papaya causes the sperm abnormalities by exhibiting acrosomal damage and mid-piece anomalies which results in complete inhibition of 
fertility in rats and mice (Rao, 1988; Chinoy et al., 1995). Aqueous crude extract of Echeveria gibbiflora on guinea pig sperm results the formation of a huge bubble by distension of the plasma membrane and dispersion of the acrosome content with disappearance of the external acrosomal membrane at the sperm head level (Delgado et al., 1999). Triptolide isolated from Tripterygium wilfordii has been reported to cause all cauda epididymal sperm to exhibit a complete absence of the plasma membrane over the entire middle and principal piece and prematured decondensation of the nuclei in rats (Hikim et al., 2000). Recent studies of a chloroform extract of Carica papaya seeds (Lohiya et al., 2002); a hydroalcoholic extract of Lantana camara leaves (de Mello et al., 2003); crude extract of A.indica leaves (Aladakatti and Nazeer Ahamed, 2005) and aqueous decoction of Chenopodium album seeds (Kumar et al., 2007) in rats and rabbits shown morphological abnormalities in the head of spermatozoa along with mid-piece anomalies. It has been suggested that the extract might cause an androgen deprived effect to target organs resulting in alterations in the internal milieu, especially of cauda epididymis (Chinoy et al., 1995).

In the present study of treated animals showed that the tail portion has balloon like cytoplasmic droplet. Ejaculates containing a high proportion of spermatozoa with attached cytoplasmic droplet can be correlated with altered epididymal function and reduced fertility (Cummins, 1973; Bedford, 1976). In the present study, high proportion of spermatozoa with attached cytoplasmic droplets in treated animals may be due to altered epididymal function. Similar observations were made in studies of combination of progestagen and androgen, Carica papaya, vincristine and cytotoxic and xenobiotic agents treated rats (Rao and Roy, 1993; Chinoy et al., 1995; Akbarsha and Averal, 1996; Akbarsha et al., 2000). A recent studies of aflatoxin B (1), a food borne mycotoxin and alcohol seed extract of Momordica charantia revealed that a higher percentage of cauda epididymal spermatozoa retained the cytoplasmic droplets in the albino mouse and rats respectively (Agnes and Akbarsha, 2003; Girini et al., 2005). The sperm cytoplasmic droplets contained electron-dense spherical inclusions, which were hypothesized as lipid inclusions produced from the lamellae through the spherical vesicles of the cytoplasmic droplets (Agnes and Akbarsha, 2003). It is known that spermatozoa carrying cytoplasmic droplets would be inhibited in motility and may not fertilize the ova (Hermo et al., 1988).

Thus, in present study, based on SEM and sperm parameter observations, it can be suggested that morphological changes in the head and tail region of cauda epididymal spermatozoa and changes in sperm parameters in male albino rats on different concentration treatment with benzene extract of $O$. sanctum leaves may be due to general disturbance of proteins and alteration in the epididymal milieu probably due to androgen deficiency consequent upon the antiandrogenic property of benzene extract of $O$. sanctum leaves. However, these conclusions are based on the preliminary study, where the rats are force fed with the benzene extract of $O$. sanctum leaves. More refined and sophisticated study is needed for identification of active constituents present in the benzene leaf extract and their effects on androgen dependent parts of the spermatozoa in albino rats which are under progress.

\section{ACKNOWLEDGEMENTS}

The authors are also acknowledge the Scanning Electron Microscope unit, CFTRI, Mysore and research facilities from Department of Post graduate studies and research in Zoology, Karnatak University, Dharwad. India.

\section{REFERENCES}

Agnes VF, Akbarsha MA. (2003) Spermatotoxic effect of aflatoxin B(1) in the albino mouse. Food Chem. 
Toxicol. 41, 119-130.

Akbarsha MA, Manivannan B, Shahul HK, Vijayan B. (1990) Antifertility effect of Andrographispaniculata (Nees) in male albino rats. Indian J. Exp. Biol. 28, 421426.

Akbarsha MA, Averal HI. (1996) Spermatotoxic effect of vincristine: A ultrastructural study in therat. Biomedical Lett. 54, 239-246.

Akbarsha MA, Latha PN, Murugaian P. (2000) Retention of cytoplasmic droplet by rat cauda epididymal spermatozoa after treatement with cytotoxic and xenobiotic agents. J. Reprod. Fertil. 120, 385-390.

Aladakatti RH, Nazeer Ahamed R. (1999) Effect of Azadirachta indica leaves on rat spermatozoa. Indian J. Exp. Biol. 37, 1251-1254.

Aladakatti RH, Nazeer AR, Mukthar A, Ghodesawar MG. (2001) Sperm parameters changes induced by Azadirachta indica in albino rats. J. Basic and clinic. Physiol. and Pharmacol. 12, 69-77.

Aladakatti RH, Nazeer AR. (2005) Ultrastructural changes in Leydig cell and cauda epididymal spermatozoa induced by Azadirachta indica leaves in albino rats. Phytother. Res. 19, 756-766.

Bauer JD, Ackermen PG, Toro G. (1974) Clinical Laboratory Methods. C.V. Mosty co., St. Louis.

Besley MA, Eliarson R, Gallegos AJ, Moghissi KS, Paulsen CA, Prasad MRN. (1980) Laboratory manual for the examination of human semen and semen cervical mucus interaction. WHO Press concern, Singapore.

Blaquier JAT. (1971) The intra cellular binding of androgens in rat epididymis. Acta. Physiol. Latinoam. 21, 101.

Bedford JM. (1976) Adaptations of male reproductive tract and the fate of spermatozoa following vasectomy in the rabbit, rhesus monkey, hamster and rat. Biol. Reprod. 14, 118-142.

Brooks DE. (1981) Metabolic activity in the epididymis and its regulation by androgens. Physiol. Rev. 61, 515.

Chinoy NJ, Geetha RM. (1983) Antiandrogenic and antifertility effect of Vinca rosea leaf extract on male albino rats. J. Comp. Physiol. Ecol. 8, 41.

Chinoy NJ, D'Souza TM, Padman P. (1995) Contraceptive efficacy of Carica papya seed extract in male mice (Mus musculus). Phytothera. Res. 9, 30-36.

Cummins JM. (1973) The effect of artificial cryptorchidism in the rabbit on the transport and survival of spermatozoa in the female reproductive tract. J. Reprod. Fertil. 33, 469-479.

Dalsenter PR, Cavalcanti AM, Andrade AJ, Araújo SL, Marques MC. (2004) Reproductive evaluation of aqueous crude extract of Achillea millefolium L. (Asteraceae) in Wistar rats. Reprod. Toxicol. 18, 819823.

De Mello FB, Jacobus D, De Carvalho KC, De Mello JR. (2003) Effects of Lantana camara(verbenaceae) on rat fertility. Vet. Hum. Toxicol. 45, 20-23.

Dyson AL, MB Orgebein - Crist MC. (1973) Effect of hypophysectomy, castration and androgen replacement upon the fertilizing ability of rat epididymal spermatozoa. Endocrinology 93, 391.

Delgado NM, Ramirez JT, Hernandez AO, Merchant Larios, H, Sanchez-Vasquez ML, Ramirez G, Reyes R. (1999) Effects of a purified fraction from Echeveria gibbiflora aqueous crude extract on guinea pig spermatozoa. Phytothera. Res. 3, 46-49.

El-Ashmawy IM, Saleh A, Salama OM. (2007) Effects of marjoram volatile oil and grape seed extract on ethanol toxicity in male rats. Basic Clin. Pharmacol. Toxicol. 101, 320-327.

El-Dwairi, QA Banihani SM. (2007) Histo-functional effects of Peganum harmala on male rat's spermatogenesis and fertility. Neuro. Endocrinol. Lett. 28, 305-310.

Girini, MM, Ahamed RN, Aladakatti RH. (2005) Effect of graded doses of Momordica charantia seed extract on rat sperm: scanning electron microscope study. J. Basic Clin. Physiol. Pharmacol. 16, 53-66.

Gupta RS, Kachhawa JB. (2007) Evaluation of contraceptive activity of methanol extract of Dendrophthoe falcata stem in male albino rats. J. Ethnopharmacol. 112, 215-218.

Gopalkrishnan K, Hinduja IN, Anandkumar TC. (1989) Pinheads (headless) spermatozoa as markers in fertile and infertile men. Adv. Contra. Deliv. Syst. 5, 361-368.

Gopalkrishnan K, Hinduja IN, Anandkumar TC. (1992) Volume of semen as a parameter of its quality. Indian J. Med. Res. 96, 215-218.

Hermo L, Dworkin J, Oko R. (1988) Role of epithelial clear cells of the rat epididymis in the disposal of the contents of cytoplasmic droplets detached from spermatozoa. Am. J. Anat. 183, 107-124. 
HikimAP, Le YH, Wang C, Reutrakul V, Sangsuwan R, Swerdloff RS. (2000) Post testicular antifertility action of triptolide in the male rat: evidence of severe impairment of cauda epididymal sperm ultrastructure. J. Androl. 21, 431-437.

KashinathanS, Ramakrishna S, Basu SL (1972) Antifertility effect of Ocimum sanctum Linn. Indian J. Exp. Biol. 10, 23-45.

Katz DF, Diel L. Overstreet JW. (1982) Differences in the moment of morphologically normal and abnormal human seminal spermatozoa. Biol. Reprod. 26, 566570.

Kirtikar K R, Basu BD. (1975) In: Medicinal Plants (eds Blatter, E., Cains, J. F., Mhaskar, K. S.), Vivek Vihar, New Delhi.

Khanna SK, Gupta SR, Grover JK (1986) Effect of long term feeding of Tulsi (Ocimum sanctum L.) on reproductive performance of adult albino rat. Indian J. Exp. Biol. 24, 302-304.

Kantak NM, Gogate MG (1992) Effect of short term administration of Tulsi (Ocimum sanctum Linn.) on reproductive behaviour of adult male rats. Indian J. Physiol. Pharmacol. 36, 109-111.

Khouri NA, El-Akawi Z. (2005) Antiandrogenic activity of Ruta graveolens L in male Albino rats with emphasis on sexual and aggressive behavior. Neuro. Endocrinol. Lett. 26, 823-829.

Kusemiju O, Noronha C, Okanlawon A. (2002) The effect of crude extract of the bark of Carica papaya on the seminiferous tubules of male Sprague-Dawley rats. Niger. Postgrad. Med. J. 9, 205-209.

Kumar S, Biswas S, Mandal D, Roy HN, Chakraborty S, Kabir SN, Banerjee S, Mondal NB. (2007) Chenopodium album seed extract: a potent spermimmobilizing agent both in vitro and in vivo. Contraception 75, 71-78.

Lohiya NK, Mishra PK, Pathak N, Manivannan B, Bhande SS, Panneerdoss S, Sriram S. (2005) Efficacy trial on the purified compounds of the seeds of Carica papaya for male contraception in albino rat. Reprod. Toxicol. 20, 135-48.

Lohiya NK, Manivannan B, Garg S. (2006) Toxicological investigations on the methanol sub-fraction of the seeds of Carica papaya as a male contraceptive in albino rats. Reprod. Toxicol. 22, 461-468.

Lohiya NK, Manivannan B, Mishra PK, Patak N, Sriram S, Bhande SS, Panneerdas S. (2002) Chloroform extract of Carica papaya seeds induces long-term reversible azoospermia in langur monkey. Asian J. Androl. 4, 17-26.

Macleod J. (1970) The significance of deviations in human sperm. In: Human testis. E. Rosenberg, and C.A. Paulsen (eds.). Plenum. New York, p. 481.

Malini T, Vanitha KG, Megala N, Annusuya S, Devi K, Elango V. (1985) Effect of Foeniculum vulgare Mill. Seed extract on the genital organs of male and femele rats. J. Physiol. Pharmacol. 29, 314.

Mukhtar A, Nazeer AR, Aladakatti RH, Ghodesawar MG. (2002) Reversible antifertility effect of benzene extract of Ocimum sanctum leaves on sperm parameters and fructose content in rats. J. Basic $\mathcal{E}$ Clinical Physiol. Pharmacol. 13, 51-59.

Murugavel T, Ruknudin A, Thangavelu S, Akbarsha MA. (1989) Antifertility effect of Vinca rosea (Linn) leaf extract on male albino mice. A - sperm parametric study. Curr. Sci. 58, 1102-1103.

Morton DB. (1975) Acrosomal enzymes. Immunochemical localization of acrosin and hyaluronidase in ram spermatozoa. J. Reprod. Fertil. 45, 375-378.

Nadkarni AK (1954) Nadkarni's Indian meterica medica. Vol.I, II, III ed. Popular Book Depot, Bombay, p.868.

Parveen S, Das S, Kundra CP, Pereira BM. (2003) A comprehensive evaluation of the reproductive toxicity of Quassia amara in male rats. Reprod. Toxicol. 17, 45-50.

Ratnasooriya WD. (1984) Effect of Atropine on fertlity of female rat and sperm motiliity. Indian J. Exp. Boil. 22, 463-466.

Rogers BJ, Bentwood BJ, Van CH, Helmbreeht G, Soderdahl D, Hale RW. (1983) Sperm morphology assessment as an indicator of human fertilizing capacity. J. Androl. 4, 119.

Rajalakshmi M, Sukanya V, Ramakrishnan PR, Kaur J. (1990) Effect of dihydrotestosterone on ultrastructural changes in rhesus monkey spermatozoa. Andrologia. 22, 144-151.

Rao MV, Roy GK. (1993) Biochemical and morphological changes of spermatozoa in progestin and androgen injected rats. Indian J. Exp. Biol. 31, 12-15.

Rao MV. (1988) Effect of alcoholic extract of Solanum xanthocarpum seeds in adult male rats. Indian J. Exp. Biol. 26, 95-98.

Seth SD, Johri N, Sundaram KR. (1981) Antispermatogenic effect of Ocimum sanctum. Indian J. 
Exp. Biol. 19, 975-976.

Setty BS, Rair SS, Kar AB. (1977) Androgenic control of epididymal function in rhesus monkey and rabbit. Fertil. Steril. 28, 674-681.

Sardessai SR, Borker, AS, Abraham ME. (1999) Effects of short term administration of Tulsi leaves on sexual behaviour in female rats. Indian J. Physiol. Pharmacol. 43, 398-400.

WHO Protocol, LG-06 (1983) Extraction and fractionation for biological and phytochemical studies. A.P.J.F/ I.P, A, pp 1001-1083. 